interests, criteria for authorship, trial registration, and duplicate publication that need to be understood by editors and adhered to in the journal. In this 60th year, Thorax's impact factor has now risen to the highest ever at 6.15 and is second only to the American Journal of Respiratory and Critical Care Medicine. Although the concept of journal impact factor is not ideal, this measure is now used in many research assessment processes all over the world and is important to authors. Both past and current editors have received wise advice and support on many of these topics from the editorial teams of the BMJ Publishing Group who, with the British Thoracic Society (BTS), have co-owned Thorax since the 1970s. On the other hand, both organisations have allowed us and past editors complete editorial freedom for which we are very grateful. Thorax is now based in BMA House and this has some obvious advantages for us with the direct availability of professional expertise. The current Thorax
To celebrate the 60th birthday of Thorax, a special symposium will be held at the British Thoracic Society Winter Meeting in the Abbey Room at the Westminster Conference Centre, Westminster, London on Friday 8 December 2006 at 11 am.

editors meet on Thursdays at BMA House with the Thorax management team to discuss all potentially acceptable papers, correspondence from authors, rebuttals (please not too many!), commission editorials, and discuss the educational content of the journal.

In ending, I would like to echo the words of John Robertson who ends his article with this comment: "Although the work of an editor is what they make of it, no one should take it on who is not proud of the honour bestowed on them by our Society". The present editors are immensely grateful and honoured in being appointed by the BTS and BMJ Publishing Group as editors of Thorax. The journal is only in such a strong position because of the skill, vision, and dedication of its previous editors. We are so proud that we have been allowed to continue the excellent work of our predecessors that has led to the journal's continuing international success. We are also privileged that, through the editorship, we have been able to serve our respiratory community both in the UK and abroad. Finally, I would like to ask you all to raise your glasses to Thorax, to all its achievements over the past 60 years, and to wish the journal, readers and editors a very successful next 60 years.

Thorax 2006;61:1015-1016. doi: $10.1136 /$ thx.2006.073114

Correspondence to: Professor J A Wedzicha, Thorax Editorial Office, BMA House, London WCIE 6JE, UK; j.a.wedzicha@medsch.ucl.ac. uk

\title{
Thorax in the 1960s
}

\section{A J Robertson*}

A $t$ the Spring meeting of the Thoracic Society in 1970, I summarised some of the work done after receiving over 700 papers, of which $53 \%$ had come from the UK and $45 \%$ from 40 different countries. About 40\% of all papers were rejected, the acceptance rate being $64 \%$ for those from the UK and 56\% for those from elsewhere. I do not think we ever refused anything which should have been taken, although we had almost certainly taken some which we should not have accepted.

In those 10 years our circulation rose by over $40 \%$; two thirds were exported and nearly one third of our issues went to the United States. I introduced abstracts at the beginning of a paper, but here is an example of exuberant literary inebriation:

"It seemed reasonable to suppose that marked variations in techniques would modify the parameters involved when assessing the problems caused by the omission of

*Dr John Robertson sadly died in June 2006. standard multifactorial corrections, for which appropriate measures are suggested in detail for further consideration with a view to their being finally eliminated."

The last word was "eliminated". It was.

The best results were from the Antipodes, with Australia having 19 accepted papers out of 23 and New Zealand topping the list with 7 out of 7 . This started with my only journalistic scoop. In 1963 I met Brian Barrett Boyes in Auckland and asked where his results of aortic homografts had been published. He said he had just signed the letter sending the manuscript to the American Journal of Thoracic Surgery, but it might take 9 months to get it published. After reading it and suggesting minor modifications, I promised to publish it in 2 months if he would give it to me to take home, and indeed this was the first of several papers from Green Lane Hospital.

In 196026 papers were published (10 medical, 8 physiology, 6 pathology, and 2 radiology) with a total of 179 pages. This was in addition to 33 surgical papers on
165 pages. In 1969 the number of papers published had increased to 64 ( 19 medical, 16 physiology, 25 pathology, and 4 radiology) with a total of 420 pages - plus 52 surgical papers on 330 pages.

In 1960 our paid circulation was 2423 with 536 (22\%) going to USA, while in 1969 the paid circulation was 3301 with $1054(32 \%)$ going to USA.

Thorax has always had a high standard, and you must recognise the tremendous task of those colleagues who spend many hours reading, altering, or suggesting modifications to the manuscript. Rejection letters are not easy because few of us can grace a refusal with the charm of Sir Theodore Fox when he edited the Lancet. One of my favourite helpers recently wrote just 13 words: "This paper is unethical, illiterate, and contains no scientific information of value. Reject." There was one paper from a Medical Research Council worker with 87 statistical errors.

The Editor obviously has the final say for the test and, because of an interest in nomenclature, I removed the words "râles" and "rhonchi" from every paper in those 10 years, substituting "crackles" and "wheezes". Although the work of an editor is what they make of it, no-one should take it on who is not proud of the honour bestowed on them by our Society.

I wish to thank Wisia Wedzicha for her kind invitation to send these comments.

Editor 1960-1971

Thorax 2006;61:1016.

doi: 10.1136/thx.2006.072314 